\title{
Regulation of the Anti-Sm Autoantibody Response in Systemic Lupus Erythematosus Mice by Monoclonal Anti-Sm Antibodies
}

Robert A. Eisenberg, ${ }^{*}$ David S. Pisetsky, ${ }^{\ddagger}$ Sylvia Y. Craven, ${ }^{*}$ Jane P. Grudier, ${ }^{\ddagger}$ Michael A. O’Donnell, ${ }^{\ddagger}$ and Philip L. Cohen* *Departments of Medicine and Microbiology/Immunology, University of North Carolina, Chapel Hill, North Carolina 27599; and

${ }^{\ddagger}$ Department of Medicine, Duke University, Durham, North Carolina 27706

\begin{abstract}
The administration of certain monoclonal anti-Sm antibodies (2G7, 7.13) induced most MRL/lpr mice to become anti-Sm positive by 5 mo of age, although other anti-Sm monoclonals (Y2, Y12) suppressed the spontaneous response. Positive anti-Sm antibody enhancement occurred efficiently only in MRL/lpr mice and not in other systemic lupus erythematosus mice that have little spontaneous anti-Sm production. The enhancement by anti-Sm antibodies was specific for the anti-Sm response. The mechanism of the passive antibody enhancement was apparently not isotype- or idiotype-related. The fine specificity of the anti-Sm monoclonal antibody may be essential to its enhancing or suppressing effects, since both enhancing monoclonals recognized only the $\mathrm{D}$ Sm polypeptide, whereas both suppressing monoclonals saw the $D$ and the $B$ polypeptides. Furthermore, analysis of serial bleeds from unmanipulated MRL mice that developed anti-Sm positivity showed that the D specificity almost always appeared first. We hypothesize, therefore, that those animals in which an anti-Sm response is initiated by D-specific B-cell clones can become serologically positive with the aid of a positive feedback loop. In contrast, animals in which the initial specificity is for both $B$ and $D$ peptides would be prevented from developing a full anti-Sm response. (J. Clin. Invest. 1990. 85:86-92.) mixed leukocyte reaction - monoclonal anti-Sm antibody • passive antibody • systemic lupus erythematosus mice
\end{abstract}

\section{Introduction}

Anti-Sm antibodies are specific markers of systemic lupus erythematosus (SLE) ${ }^{1}$ in humans and in murine models of this disease $(1,2)$. These autoantibodies are directed at one or more peptides of nuclear RNA-protein complexes, termed small nuclear ribonucleoproteins (snRNPs [3]), and are predominantly of the $\mathrm{IgG}$ isotypes $(4,5)$. Only a minority of humans with SLE develop this specificity; remarkably, this is also the

This work was presented in part at the 51st Annual Meeting of the American Rheumatism Association in Washington, DC, 9-13 June 1987; and at the conference on Advances in Systemic Autoimmune Diseases in Perugia, Italy, 6-9 November 1988.

Address reprint requests to Dr. Eisenberg, CB No. 7280, 932 FLOB, University of North Carolina, Chapel Hill, NC 27599-7280.

Received for publication 16 June 1989 and in revised form 5 September 1989.

1. Abbreviations used in this paper: SLE, systemic lupus erythematosus; snRNP, small nuclear ribonucleoprotein.

J. Clin. Invest.

(c) The American Society for Clinical Investigation, Inc 0021-9738/90/01/0086/07 $\$ 2.00$

Volume 85, January 1990, 86-92 case for genetically identical SLE-prone mice. We have previously investigated in detail the expression of anti-Sm antibodies in the inbred MRL mouse strains in order to elucidate this unusual pattern of autoantibody production (6). We found that 5-mo-old MRL/Mp-lpr/lpr (MRL/lpr) mice have a $25 \%$ prevalence of anti-Sm positivity, as determined by immunodiffusion. Quantitative analysis with a much more sensitive ELISA assay indicated that immunodiffusion-positive sera had high titers of anti-Sm antibodies, whereas immunodiffusion-negative sera were indistinguishable from sera obtained from normal mice. The distribution of anti-Sm positivity among a large cohort of MRL/lpr mice of known lineage showed no evidence for genetic, parental, or environmental factors that might determine whether an individual became anti-Sm positive. These data suggested that the initiation of the anti-Sm response depends on stochastic factors in the ontogeny of an individual, and that once an animal becomes positive, its response is amplified by a positive feedback system. Such stochastic factors must interact with genes in the MRL background, as only this strain spontaneously produces anti-Sm antibodies.

In the current study, we have developed a model of a feedback system by determining the effect of passively infused anti-Sm antibodies in SLE mice. Our findings confirm that some anti-Sm monoclonal antibodies can favor the further endogenous production of this specificity $(7,8)$. We have determined that this effect requires the appropriate genetic background, that it is antigen-specific, that it probably does not operate through idiotypic networks or through a single isotype, and that it probably requires recognition of particular epitopes on the $\mathrm{D}$ peptide of the Sm complex. In addition, serial analysis of the fine specificity of sera from MRL mice that spontaneously developed anti-Sm antibodies was consistent with a special role of the $D$ peptide in initiating the anti-Sm response.

\section{Methods}

Mice. MRL/Mp-lpr/lpr (MRL/lpr), MRL/Mp-+/+ (MRL/+), and C57BL/6-lpr/lpr (B6-lpr) were obtained from our colony at the University of North Carolina at Chapel Hill or directly from the Jackson Laboratory (Bar Harbor, ME). Lpr homozygous F1 hybrids were bred by crossing MRL/lpr females with B6/lpr males (MB/lpr), or B6/lpr females with $\mathrm{MRL} / \mathrm{lpr}$ males (BM/lpr). Mice were sex-matched in each experiment.

Antibodies. Monoclonal anti-Sm antibodies or control antibodies were produced as ascites in $(\mathrm{MRL} /+\times \mathrm{BALB} / \mathrm{c}) \mathrm{F} 1$ mice. They were purified on staphylococcal protein $A$ and stored frozen until use. The following antibodies were used (Table I): 2G7 (9), 7.13 (the kind gift of Dr. Sallie O. Hoch, Agouron Institute, La Jolla, CA [10]), Y2 and Y12 (the kind gift of Drs. Ethan Lerner and Joan Steitz, Yale University, New Haven, CT [11]), 5N (12), 6/0 (13), and 220 (the kind gift of Dr. Kim Hasenkruz, McLaughlin Institute, Great Falls, MT). All MAbs except 220 were originally from MRL/lpr mice.

Passive antibody protocol. Mice were prebled at the age of 4-6 wk 
Table I. Monoclonal Antibodies Utilized

\begin{tabular}{llllc}
\hline Name & Isotype & \multicolumn{1}{c}{ Specificity } & \multicolumn{1}{c}{ Source } & Reference \\
\hline $2 G 7$ & IgG2a, $\kappa$ & Sm (D) & Pisetsky & 9 \\
Y2 & IgG2a, $\kappa$ & Sm (B, D) & Steitz & 11 \\
Y12 & IgG3, $\kappa$ & Sm (B, D) & Steitz & 11 \\
7.13 & IgG3, $\kappa$ & Sm (D) & Hoch & 10 \\
220 & IgG3, $\kappa$ & H-2 & Hasenkruz & - \\
$5 N$ & IgG2a, $\kappa$ & Chromatin (DNA) & Pisetsky & 12 \\
$6 / 0$ & IgG2a, $\kappa$ & DNA & Pisetsky & 13 \\
\hline
\end{tabular}

and then injected intraperitoneally once a week with $300 \mu \mathrm{g}$ of purified monoclonal antibodies in $0.5 \mathrm{ml}$ of phosphate-buffered saline (PBS). They were bled monthly immediately before the weekly injection. Sera were tested by immunodiffusion as they were accumulated. When a mouse was determined to be anti-Sm positive, its injections were discontinued.

Assays. Anti-Sm antibodies were detected by immunodiffusion against rabbit thymus extract, as described (2). In some experiments, sera were also tested by ELISA, using affinity-purified rabbit Sm (14). The IgG subclass of anti-Sm antibodies was similarly determined by ELISA, as previously reported (5). Anti-chromatin antibodies were also measured by ELISA, using chicken erythrocyte chromatin (15).

Anti-idiotypic antibodies to the $2 \mathrm{G} 7$ monoclonal were raised by immunizing rabbits with purified 2G7. The resultant antiserum was exhaustively absorbed on a solid phase column made with the $6 / 0$ protein, an MRL anti-DNA monoclonal with the same isotype (IgG2a). Anti-idiotypic antibodies were then affinity-purified on a 2G7 column, and these antibodies were conjugated with biotin. They were further absorbed with solid-phase $6 / 0$ immediately before use. 2G7 idiotype-positive anti-Sm antibodies were detected by ELISA as follows: Affinity-purified $\mathrm{Sm}$ antigen at a predetermined optimal concentration was coated on microtiter plates in borate-buffered saline for $5 \mathrm{~h}$ at $4^{\circ} \mathrm{C}$. After blocking nonspecific binding with BSA and Tween, samples (either monoclonal antibody or sera) were added at varying dilutions. After overnight incubation, the absorbed biotinylated antiidiotype antibody was added at a 1:1000 dilution. The assay was then developed with avidin-alkaline phosphatase and substrate. This assay could detect as little as $1 \mathrm{ng}$ of the $2 \mathrm{G} 7$ antibody. Its cross-reactivity with $\mathrm{Y} 12,7.13$, or $\mathrm{Y} 2$ monoclonals was $<0.1 \%$. The results with individual sera were compared with a standard curve made with purified $2 \mathrm{G} 7$ protein and calculated as micrograms per milliliter of $2 \mathrm{G} 7$ idiotype. To determine total anti-Sm, each serum was simultaneously tested in a $\kappa$ light chain-specific anti-Sm assay and compared with a curve made with the $\mathrm{Y} 2$ protein. The $\mathrm{Y} 2$ standard was used because dilution of this protein gave an OD curve that was superimposable on that produced by diluting anti-Sm-positive sera.

Sera from passive antibody-treated MRL/lpr mice or from unmanipulated MRL mice were subjected to Western blotting as follows: Affinity-purified $\mathrm{Sm}$ was prepared for electrophoresis by boiling $1 \mathrm{vol}$ of antigen $(2 \mathrm{mg} / \mathrm{ml})$ with 1 vol of sample buffer containing $0.0625 \mathrm{M}$ Tris, $2 \% \mathrm{wt} / \mathrm{vol}$ sodium dodecyl sulfate (SDS), $5 \%$ 2-mercaptoethanol $\mathrm{vol} / \mathrm{vol}$, and $10 \% \mathrm{vol} / \mathrm{vol}$ glycerol. The diluted sample was electrophoresed on a $3.5 \%$ polyacrylamide stacking gel and $12.5 \%$ polyacrylamide resolving slab gel in an electrode buffer $(0.025 \mathrm{M}$ Tris hydroxide, $0.192 \mathrm{M}$ glycine, and $1 \% \mathrm{wt} / \mathrm{vol}$ SDS). Electrophoresis was performed at $20^{\circ} \mathrm{C}$ for $2.5 \mathrm{~h}$ at $40 \mathrm{~mA}$ per gel with constant current using a modification of the procedure described by Laemmli (16). The separated polypeptides were transferred to nitrocellulose by electroblotting in transfer buffer ( $150 \mathrm{mM}$ glycine, $25 \mathrm{mM}$ Tris hydroxide, $20 \%$ methanol, $\mathrm{pH} 8.3$ ) at $100 \%$ voltage for $1.5 \mathrm{~h}$ at $10^{\circ} \mathrm{C}$. The nitrocellulose paper was then blocked with a solution of PBS-5\% BSA for $2 \mathrm{~h}$. Strips 6 $\mathrm{mm}$ wide were cut from the nitrocellulose paper and incubated with sera diluted in blotting buffer (PBS, $0.85 \%$ Tween $80,1 \%$ BSA). The sera were used at dilutions at which they gave comparable ODs by
ELISA. After incubation with the sera, the strips were incubated with peroxidase-labeled goat anti-mouse IgG or rabbit anti-human IgG (Cappel-Worthington Biochemicals, Malvern, PA) diluted in blotting buffer to 1:500 and 1:250, respectively. The bound antibodies were visualized by adding the horseradish peroxidase color development reagent (Bio-Rad Laboratories, Richmond, CA), as suggested by the supplier.

\section{Results}

Genetics of anti-Sm induction. In preliminary experiments, we demonstrated the induction of anti-Sm antibodies in MRL/+ mice by injections of the $2 \mathrm{G} 7$ monoclonal anti-Sm. Administration of 0.3 and $0.03 \mathrm{mg}$ per mouse per week of the $2 \mathrm{G} 7$ monoclonal antibody caused most MRL/+ mice to become anti-Sm positive, whereas weekly doses of 3 and $0.003 \mathrm{mg}$ per mouse per week were ineffective (data not shown). The 0.3-mg dose was chosen for all subsequent experiments.

The detection of spontaneous anti-Sm antibody production in the presence of the passively administered antibody did not pose a problem for several reasons. $2 \mathrm{G} 7$ antibody, by itself, is not precipitating, and thus was not detected in the doubleimmunodiffusion screening. In addition, the amount of passive antibody that remained $1 \mathrm{wk}$ after injection was, in most cases, substantially less than the amount detected by ELISA in those mice that had begun endogenous production. Passive antibody administration was discontinued in those animals that had become immunodiffusion-positive, so that subsequent bleeds would have vanishingly small amounts of persisting passive antibody. Furthermore, as demonstrated below, the isotype and the idiotype of the endogenously produced anti-Sm antibody could not be explained by the passively administered material.

Passively administered anti-Sm antibody increased the likelihood of endogenous anti-Sm production preferentially in mice with the genetic capacity to produce this autoantibody spontaneously (6). As shown in Fig. 1, MRL/lpr treated with 2G7 developed the early appearance of anti-Sm antibodies ( $30 \%$ of mice positive at $12 \mathrm{wk}$ of age), and by $5 \mathrm{mo}$ of age ( 16 wk after injection) $>80 \%$ were positive. MRL/lpr mice injected with the $5 \mathrm{~N}$ control antibody developed the expected $25-30 \%$ prevalence of anti-Sm positivity at $5 \mathrm{mo}$ of age. In contrast, B6/lpr mice, which do not spontaneously produce anti-Sm antibodies, were much less affected by the $2 \mathrm{G} 7$ injections, as only a single animal became positive at 6 mo of age. $\mathrm{MB} / \mathrm{lpr}$ mice, which normally have about a $4 \%$ incidence of anti-Sm antibodies at 5 mo of age (unpublished data), tended to be intermediate in their susceptibility to anti-Sm induction by $2 \mathrm{G} 7$. Only one $\mathrm{BM} / \mathrm{lpr}$ mouse has responded, although fewer such mice have been investigated.

Effects of different monoclonal anti-Sm antibodies. Four different anti-Sm monoclonal antibodies were used in the passive-antibody experiments: $2 \mathrm{G} 7$ and Y2 (both IgG2a, $\kappa$ ), and 7.13 and $Y 12$ (both IgG3, $\kappa$ ). Isotype-matched control proteins of other specificities were also administered. As shown in Fig. 2, which illustrates pooled data from three experiments with similar results, $2 \mathrm{G} 7$ was the most potent in inducing anti-Sm antibodies, but 7.13 also had a significant effect. The control antibodies $5 \mathrm{~N}$ and 220 induced no more anti-Sm than would be expected to occur spontaneously, while the Y2 and Y12 antibodies suppressed endogenous anti-Sm production. The weekly administration of $\mathrm{Y} 2$ to- 

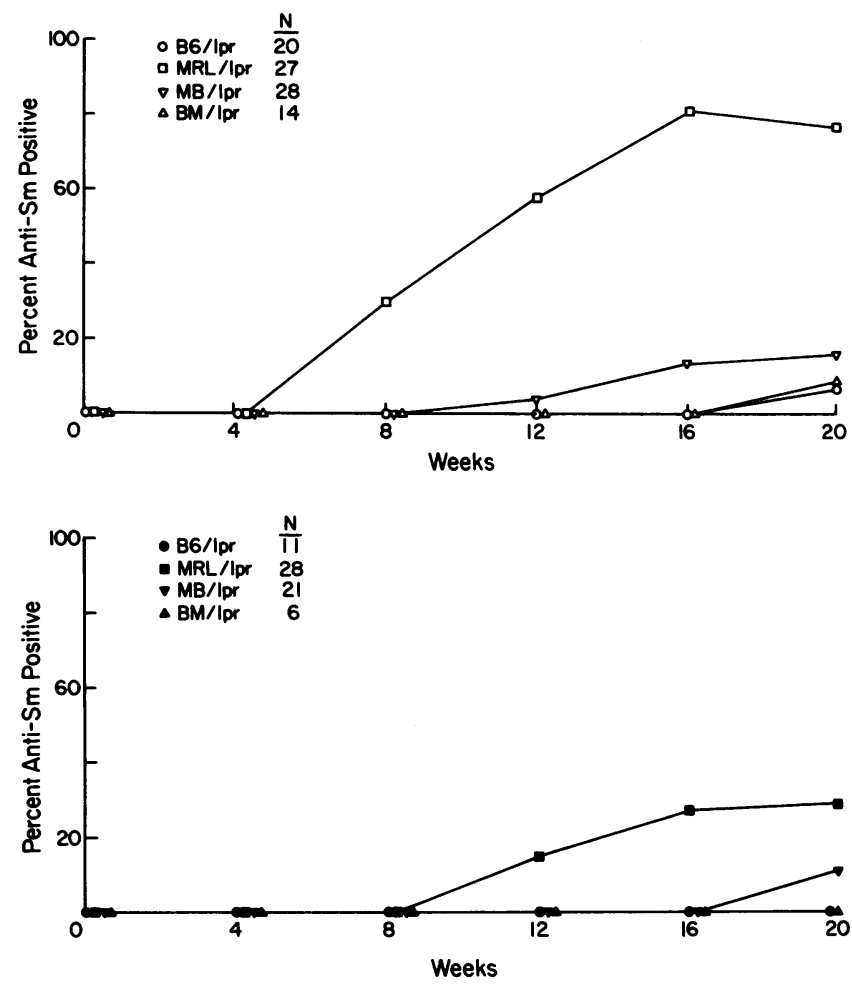

Figure 1. Genetics of anti-Sm induction by passive antibody. Animals 4-6 wk old of the indicated strains were injected intraperitoneally with $0.3 \mathrm{mg} /$ wk of (upper panel) anti-Sm (2G7) or (lower panel) control $(5 \mathrm{~N})$. Mice were bled monthly and typed for endogenous anti-Sm production by double immunodiffusion. Results shown have been pooled from three experiments with similar outcomes. The $N$ listed indicates the total number of mice entered into the experiments. The prevalence of anti-Sm positivity in the 2G7-treated MRL/lpr mice was significantly greater by $\chi^{2}$ analysis than that induced by $2 \mathrm{G} 7$ in all other groups $(P<0.001$ at 12,16 , and $20 \mathrm{wk})$ and different from that seen in 5N-treated MRL/lpr mice $(P<0.01$ at 8-20 wk). The modest induction of anti-Sm in $\mathrm{MB} / \mathrm{lpr}$ mice by $2 \mathrm{G} 7$ did not reach statistical significance in comparison with the B6/ lpr and $\mathrm{BM} / \mathrm{lpr}$ groups.

gether with $2 \mathrm{G} 7$, each at a dose of $0.3 \mathrm{mg}$, gave an incidence of anti-Sm similar to that produced by $\mathrm{Y} 2$ alone.

The comparisons shown in Fig. 2 were confirmed by ELISA (not shown). Interestingly, the amounts of anti-Sm antibody in immunodiffusion-positive sera did not depend on the mode of induction (Table II), except for somewhat lower values in 7.13-treated animals $(P<0.05)$.

The differing effects of the various monoclonals tested suggested a possible role for isotype or idiotype in the induction of anti-Sm. However, the fact that monoclonals of two isotypes (IgG2a, IgG3) could either induce anti-Sm (2G7, 7.13) or suppress anti-Sm (Y2, Y12) argued against a simple isotype-related mechanism. In addition, the relative IgG subclass distribution of anti-Sm antibodies in mice receiving $2 \mathrm{G} 7$ or 7.13, and in controls was remarkably consistent (Fig. 3). This would not be expected if, for example, the mechanism of $2 \mathrm{G} 7$ anti-Sm induction involved isotype-specific $\mathrm{T}$ cell help or suppression (17).

The possibility that idiotype network interactions might play a role in passive antibody induction of anti-Sm was investigated by measuring the level of $2 \mathrm{G} 7$ idiotype in treated

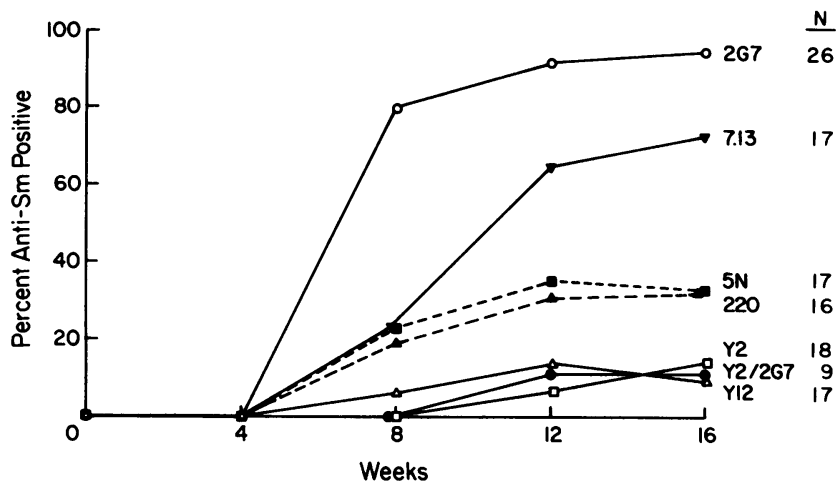

Figure 2. Effects of different MAb on induction of anti-Sm in MRL/ lpr mice. MRL/lpr mice 4-6 wk old were treated with weekly injections of $0.3 \mathrm{mg}$ per mouse of anti-Sm (solid lines) or control monoclonals (dashed lines). Anti-Sm positivity was determined by immunodiffusion. Results represent pooled data from three experiments with similar results. $N$ indicates the total number of mice initiated into each group. The effects of $2 \mathrm{G} 7$ in inducing anti-Sm were greater than all other monoclonals $(P<0.001)$ for $8-16 \mathrm{wk}$, except vs. 7.13 at $12 \mathrm{wk}(P=0.05)$ and at $16 \mathrm{wk}$ (not significant). The 7.13-treated group had a significantly higher prevalence of anti-Sm than the Y12 group at 12 and $16 \mathrm{wk}(P<0.01)$ and was significantly greater than the pooled results of the control proteins $(5 \mathrm{~N}+220)$ at 12 and 16 wk $(P=0.05)$. The $\mathrm{Y} 2$ group had significantly less anti-Sm than the $5 \mathrm{~N}$ group $(P<0.05$ at 8 and $12 \mathrm{wk})$, while the difference between the Y12 group and the control proteins did not reach statistical significance.

and untreated MRL/lpr mice. Table III shows that the prebleed sera had very little anti-Sm antibody or 2G7 idiotype. At $4 \mathrm{wk}$ after the initiation of injections, passively carried-over anti-Sm was detectable. In those animals treated with $2 \mathrm{G} 7$, a mean of $19 \mu \mathrm{g} / \mathrm{ml}$ of anti-Sm was present, and of this, 7.9 $\mu \mathrm{g} / \mathrm{ml}$ was $2 \mathrm{G} 7$ idiotype positive. The other groups had smaller amounts of anti-Sm activity, with essentially no 2G7 idiotype activity. Mice that had initiated their own endogenous production of anti-Sm and had gone for at least a month without passive anti-Sm had much higher levels of anti-Sm than was seen early in the course of the experiment. However, the amount of 2G7 idiotype-bearing anti-Sm antibodies of these mice was still very low, even in the group that had been treated with $2 \mathrm{G} 7(1 \mu \mathrm{g} / \mathrm{ml}$ on the average).

Specificity of anti-Sm passive enhancement. The enhanced endogenous anti-Sm antibody production resulted from the injection of certain anti-Sm antibodies, but not from the injection of antibodies of other specificities (see Fig. 2). Con-

Table II. Anti-Sm Levels by ELISA in Anti-Sm Immunodiffusion-positive Mice*

\begin{tabular}{lrc}
\hline Treatment & $n$ & ${\text { Mean } \mathrm{OD}_{405}( \pm \mathrm{SD})} \mathrm{n}$ \\
$2 \mathrm{G} 7$ & 13 & $1.558( \pm 0.602)$ \\
7.13 & 8 & $1.015( \pm 0.396)$ \\
$5 \mathrm{~N}, 220$ & 9 & $1.803( \pm 0.743)$ \\
$\mathrm{Y} 2, \mathrm{Y} 12$ & 3 & $1.934( \pm 0.896)$
\end{tabular}

* Immunodiffusion anti-Sm-positive 5-mo bleed sera were tesed at a dilution of $10^{-4}$. 


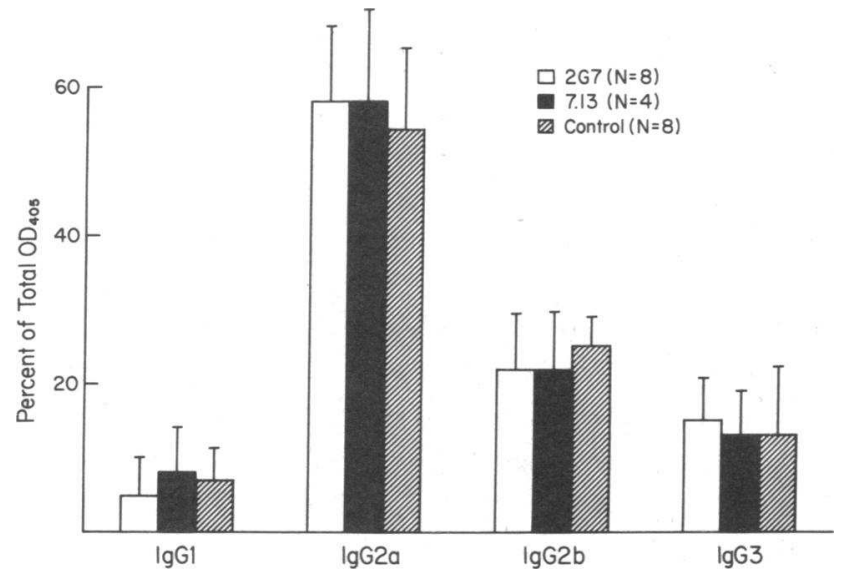

Figure 3. IgG subclass distribution of anti-Sm antibodies in MRL/ lpr mice. Anti-Sm-positive sera from MRL/lpr mice in which monoclonal antibody treatment had ceased at least 1 mo previously were tested in an isotype-specific anti-Sm ELISA. Mice had been treated with 2G7 (open bars), 7.13 (solid bars), or, as controls, $5 \mathrm{~N}, 220$, or PBS (striped bars). The percent of each isotype as compared to the total OD for all four IgG subclasses was determined. There were no differences among the three groups in their subclass distribution. Error bars represent standard deviations.

versely, the enhancement of anti-Sm autoantibody expression induced by these anti-Sm antibodies did not affect the titers of anti-chromatin antibodies (data not shown). In addition, the $5 \mathrm{~N}$ monoclonal antibody, which recognizes chromatin, did not enhance endogenous anti-chromatin production over that seen in PBS-treated mice. The course of autoimmune disease, as determined by survival, was modestly accelerated in 2G7treated mice (Fig. 4).

Specificity of anti-Sm antibodies. The specificity of anti$\mathrm{Sm}$ antibodies was determined by Western blotting. Fig. 5 shows the blots obtained with the monoclonal antibodies utilized. As has been reported, the 2G7 and 7.13 antibodies recognized the D peptide, while the Y2 and Y12 antibodies saw

Table III. 2 G7 Idiotype in Anti-Sm-positive Passive Antibody-treated Mice

\begin{tabular}{llll}
\hline & \multicolumn{3}{c}{ Treatment } \\
\cline { 2 - 4 } \multicolumn{1}{c}{ Bleed } & \multicolumn{1}{c}{$\begin{array}{c}2 G 7 \\
(n=15)\end{array}$} & $\begin{array}{c}\text { Other anti-Sm } \\
(n=12)\end{array}$ & \multicolumn{1}{c}{$\begin{array}{c}\text { Control }^{*} \\
(n=12)\end{array}$} \\
\hline & & $\mu g / m l$ by ELISA \\
Prebleed & & & \\
$\quad$ Anti-Sm & & & \\
$\quad$ Idiotype & $0.8( \pm 0.8)$ & $0.8( \pm 0.6)$ & $0.7( \pm 0.8)$ \\
4 wk & $0( \pm 0)$ & $0.02( \pm 0.07)$ & $0( \pm 0)$ \\
Anti-Sm & $19( \pm 13)$ & $6( \pm 6)$ & $7( \pm 17)$ \\
$\quad$ Idiotype & $7.9( \pm 8.2)$ & $0( \pm 0)$ & $0.02( \pm 0.05)$ \\
Immunodiffusion positive & & & \\
$\quad$ Anti-Sm & $553( \pm 673)$ & $274( \pm 206)$ & $570( \pm 641)$ \\
Idiotype & $1.0( \pm 1.8)$ & $0.7( \pm 1.0)$ & $0.4( \pm 0.5)$
\end{tabular}

* Selected mice that had been treated with Y2, Y12, or 7.13 and had become anti-Sm positive.

¥ Selected mice that had been treated with $5 \mathrm{~N}, 220$, or PBS and had become anti-Sm positive.

First bleed after mouse became anti-Sm positive and injections had been stopped.

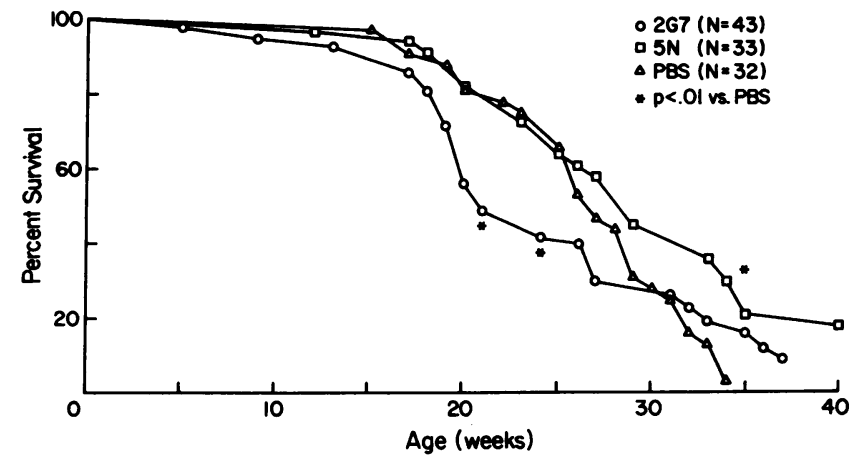

Figure 4. Survival of passive antibody-treated mice. Mortality data were pooled from five separate, similar experiments. Enhanced mortality in the 2G7-treated animals was significant at the ages of 21-24 wk $(P<0.01)$.

both the B and D peptides (10,18, 19). Fig. 6 shows representative blots from passive antibody-induced sera. Even though the inducing antibody $(2 \mathrm{G} 7)$ only saw the $D$ peptide, the resultant positive sera saw at least one additional epitope, present on the B and B' peptides, and by Western blot were indistinguishable from anti-Sm-positive sera from unmanipulated mice.

These results were compared with Western blots of serial bleeds of MRL/lpr and MRL/+ mice that spontaneously developed anti-Sm reactivity. Seven $M R L / l p r$ and six $M R L /+$ were studied. All the MRL/+ recognized the $D$ band at the time of the initial anti-Sm response. Five of the sera reacted

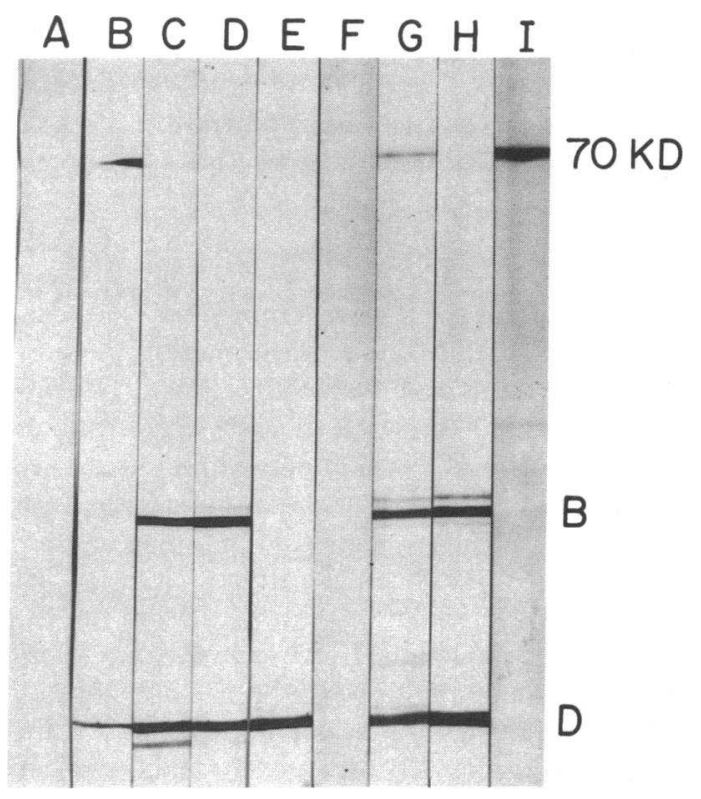

Figure 5. Western blot of anti-Sm antibodies used in passive antibody experiments. Purified Sm/RNP antigen was run on polyacrylamide gels, transferred to nitrocellulose, and probed with the following reagents: lane $A$, UPC 10, an IgG2a myeloma protein; lane $B$, 2G7; lane $C$, Y2; lane $D, \mathrm{Y} 12$; lane $E$, 7.13; lane $F$, BALB/c serum; lane $G$, anti-Sm-positive MRL/lpr serum; lane $H, C D C$ anti-Sm standard; lane $I, C D C$ anti-RNP standard. The staining by $2 G 7$ of a high-molecular-weight band with the same mobility as that seen by the anti-RNP serum was not consistent. 


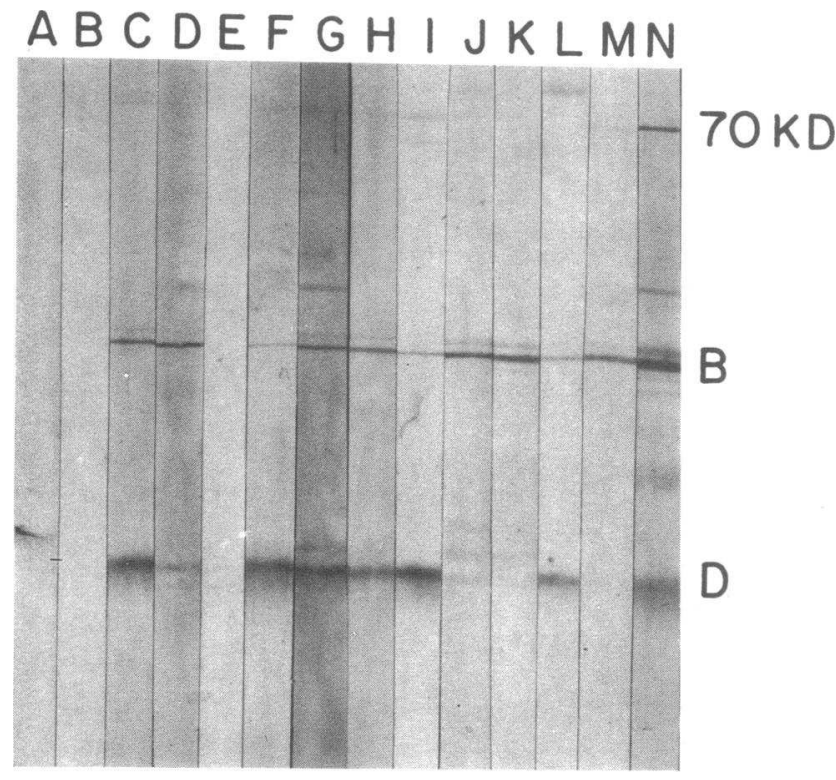

Figure 6. Immunoblot of passive antibody-induced anti-Sm autoantibodies. Sera from MRL/lpr mice making endogenous anti-Sm in response to passive antibody induction with $2 \mathrm{G} 7$ were diluted to equivalent potency on the basis of anti-Sm ELISA assays and tested by Western blot on a purified rabbit Sm antigen: $(A)$ BALB/c serum; (B) UPC10; $(C-M)$ various passive antibody-induced sera; $(N)$ human SLE standard. The positions of the $B$ and the $D$ peptides are marked.

only with the $\mathrm{D}$ band, while one serum also reacted with the $\mathrm{B}$ band and the 70-kD RNP band. Six of the seven MRL/lpr reacted only with the $D$ band initially, and five of these six bound additional bands in later bleeds, mainly the B and $\mathrm{B}^{\prime}$. One serum did not show any positivity by blot. Fig. 7 shows anti-Sm Western blots of serial sera from one of these MRL/ lpr mice which spontaneously acquired anti-Sm.

\section{Discussion}

We have demonstrated that the passive administration of certain monoclonal anti-Sm antibodies induced endogenous production of anti-Sm in genetically susceptible mice. This induction was specific for anti-Sm, as anti-Sm-injected animals had no enhancement of production of anti-chromatin. Mice injected with anti-chromatin monoclonal antibody or with other monoclonals did not have enhanced anti-Sm production. The anti-chromatin monoclonal antibody utilized, $5 \mathrm{~N}$, which recognizes the DNA moiety of chromatin, did not enhance anti-chromatin production. However, we cannot conclude that the chromatin autoantibody system is not susceptible to the same kind of regulation until a much larger number of antibodies is tested, particularly because half of the anti-Sm antibodies used did not induce endogenous anti-Sm production. A similar observation of passive antibody induction of autoantibody was reported in humans for the $\mathrm{Rh}$ determinants (20). The possibility of such passive antibody regulation in other autoantibody responses remains to be investigated.

The current work suggests some aspects of the mechanism of this antibody enhancement in the anti-Sm antibody system. First, idiotypic networks do not appear to be involved. There was no enhancement of production of the $2 \mathrm{G} 7$ idiotype in $2 \mathrm{G} 7$

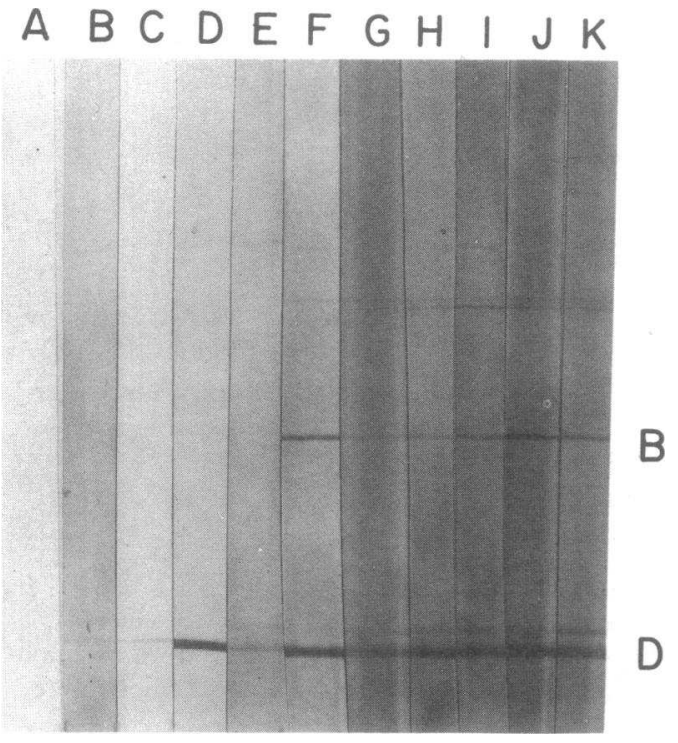

Figure 7. Immunoblots on sequential sera from an anti-Sm-positive MRL/lpr mouse. Serial sera from an individual MLR/lpr mouse were tested at dilutions "normalized" by ELISAs on Western blots where a purified rabbit $\mathrm{Sm}$ was utilized as antigen. $(A) \mathrm{BALB} / \mathrm{c}$ serum; $(B-K)$ serial bleeds on the individual MRL/lpr mouse. Bleeds were taken at $9,10,12,13,15,18,21,24,28$, and 32 wk of age, respectively.

passive antibody-induced mice. It is possible, however, that the rabbit anti-2G7 anti-idiotypic reagent reacted with an idiotope of the $2 \mathrm{G} 7$ antibody that was not relevant to in vivo idiotype regulation. Thus, in an MRL/lpr mouse there could be enhancement by $2 \mathrm{G} 7$ of idiotopes expressed on the $2 \mathrm{G} 7$ molecule different from the idiotopes recognized by our rabbit anti-idiotype reagent. We feel that this is unlikely, but it can be ruled out only by study of the $V_{H}$ and $V_{K}$ genes utilized. Secondly, it is unlikely that there is a specific role for isotype. Other investigators have published that the IgG2a isotype is capable of enhancing an immune response to exogenous antigen when given with the immunogen, but that other isotypes are immunosuppressive $(21,22)$. In the current work, however, the anti-Sm monoclonal antibodies that were capable of positive enhancement were of the IgG2a and IgG3 isotypes, whereas two anti-Sm monoclonals of the same isotypes appeared to be suppressive. Thirdly, the peptide specificities of the induced antibodies, as determined by Western blotting (Fig. 6), suggest that the Sm antigenic particle is involved in the mechanism of passive antibody enhancement. A role for $\mathrm{Sm}$ antigen would explain the induction of $\mathrm{B} / \mathrm{B}^{\prime}$ specific antibodies by a mAb that sees only the $\mathrm{D}$ peptide. In this regard, the relationship of the monoclonal antibody specificity to its enhancing capability is particularly striking. Those monoclonals that recognized only the $D$ peptide were enhancing, whereas those monoclonals that recognized both the $B$ and the $D$ peptides, presumably through cross-reactive epitopes, were suppressive. These results suggest that the specificity of the monoclonal antibody determines its ability to enhance. Although further anti-Sm monoclonals and additional doses need to be tested to confirm this interpretation, this analysis parallels the findings of Haughton and Makela (23), who showed that antibodies that recognized a limited number of determinants on 
an antigenic particle could enhance an immune response, whereas antibodies that recognized a larger set of determinants were suppressive. In addition, the two enhancing anti-Sm monoclonals published by Maini and coworkers were $D$ specific $(7,8)$.

The special role of D-peptide recognition suggested by the monoclonal antibody-enhancement experiments parallels results in sequential analyses by Western blotting of sera from MRL mice that spontaneously developed anti-Sm antibodies. In every case, the initial positive serum recognized the $D$ peptide, and in all of these sera except one only the $D$ peptide was seen. Similar results have also been reported in a single SLE patient who by chance had serial bleeds through the time she became anti-Sm positive (24). Although the immunoblot technique only detects a subset of the antibodies reacting with a particular antigen, these results suggest that the spontaneous anti-Sm response begins with recognition of the $D$ peptide. The initial anti-D response could then engender an antibodymediated enhancement mechanism such as we have demonstrated.

These current results, along with our previous findings, allow us to formulate a more detailed hypothesis regarding the mechanism of anti-Sm production in SLE mice. We have previously shown that spontaneous anti-Sm occurs only in certain SLE mouse strains. Efficient induction of this specificity by passive antibody requires these same strains. This suggests that the genetic background determines certain common aspects of immunoregulation of the spontaneous and passiveantibody-induced anti-Sm responses. Even in mice with this genotype (MRL), the frequency of precursor B cells for antiSm production is very low (25). However, as our Sm-antigen immunization experiments have shown, these B cells must arise periodically, and under the appropriate conditions will go on to make an anti-Sm response $(26,27)$. We hypothesize that a spontaneous anti-Sm response requires the initial stimulation of B cells specific only for the D peptide. If anti-Sm antibodies of this unique specificity are thus expressed, a positive feedback loop is initiated, and the anti-Sm response is amplified until it becomes serologically detectable. If, on the other hand, the initial antibodies produced in response to the Sm particle bind both the $B$ and the $D$ peptides, then a negative feedback loop intervenes and prevents amplification of the response. As the combined effect of equivalent amounts of the enhancing antibody and the suppressing antibody appears to be suppressive, any response which initially included an antiSm antibody of the Y2 type (anti-B, D) would fail to be amplified.

This schema fits with the role we postulate for stochastic events in lymphocyte ontogeny that determine the anti-Sm seropositivity of an MRL SLE mouse (6). According to this admittedly oversimplified speculation, the chance of an individual MRL/lpr animal developing an initial D peptide-specific response before the age of 5 months is $\sim 25 \%$. That animal would become anti-Sm seropositive. On the other hand, the probability is $75 \%$ that an individual animal will initially express B/D-specific clones, such that the response would be turned off. These specificities could be determined by the random selection and somatic mutation of immunoglobulin variable region genes. The level of influence of the MRL genetic factors presumably mainly occurs after this selection of the B-cell anti-Sm specificity and functions through as yet not understood immunoregulatory mechanisms.
Our current findings are paralleled by work from Maini and co-workers $(7,8)$. They have published similar results with enhancement of the anti-Sm response in MRL/lpr mice. However, they also claimed that the anti-Sm-treated animals lived longer than controls; we do not confirm this finding with a larger number of animals, and in fact we find a modestly decreased survival in anti-Sm-treated mice. These apparently conflicting results may well be due to the different monoclonal antibodies used in the two studies.

\section{Acknowledgments}

We thank Wendy Dower and Anita Washam for excellent secretarial help.

This work was supported by National Institutes of Health grants AR-34156, AR-26574, AR-33887, and AI-23308, and the Medical Research Service, Veterans Administration. Dr. Cohen was a Senior Investigator of the Arthritis Foundation.

\section{References}

1. Notman, D. D., N. Kurata, and E. M. Tan. 1975. Profiles of antinuclear antibodies in systemic rheumatic diseases. Ann. Intern. Med. 83:464-469.

2. Eisenberg, R. A., E. M. Tan, and F. J. Dixon. 1978. Presence of anti-Sm reactivity in autoimmune mouse strains. J. Exp. Med. 147:582-587.

3. Lerner, M. R., and J. A. Steitz. 1981. Snurps and scyrps. Cell. 25:298-300.

4. Eisenberg, R. A., K. Dyer, S. Y. Craven, C. R. Fuller, and W. J. Yount. 1985. Subclass restriction and polyclonality of the systemic lupus erythematosus marker antibody anti-Sm. J. Clin. Invest. 75:1270-1277.

5. Eisenberg, R. A., J. B. Winfield, and P. L. Cohen. 1982. Subclass restriction of anti-Sm antibody in MRL mice. J. Immunol. 129:21462149.

6. Eisenberg, R. A., S. Y. Craven, R. W. Warren, and P. L. Cohen. 1987. Stochastic control of anti-Sm autoantibodies in MRL/Mp-lpr/ Ipr mice. J. Clin. Invest. 80:691-697.

7. Brennan, F. M., D. G. Williams, D. Bovill, M. R. Stocks, and R. N. Maini. 1986. Administration of monoclonal anti-Sm antibody prolongs the survival and renal function of MRL-lpr/lpr mice. Clin. Exp. Immunol. 65:42-50.

8. Stocks, M. R., D. G. Williams, and R. N. Maini. 1987. Differential induction of lupus-associated antinuclear antibodies in MRL mice by monoclonal anti-Sm antibodies. Clin. Exp. Immunol. 67:492-499.

9. Pisetsky, D. S., S. O. Hoch, C. L. Klatt, M. A. O'Donnell, and J. D. Keene. 1985. Specificity and idiotypic analysis of a monoclonal anti-Sm antibody with anti-DNA activity. J. Immunol. 135:40804085.

10. Billings, P. B., J. R. Barton, and S. O. Hoch. 1985. A murine monoclonal antibody recognizes the 13,000 molecular weight polypeptide of the $\mathrm{Sm}$ small nuclear ribonucleoprotein complex. J. Immunol. 135:428-432.

11. Lerner, E. A., M. R. Lerner, C. A. Janeway, and J. A. Steitz. 1981. Monoclonal antibodies to nuclear acid-containing cellular constituents: probes for molecular biology and autoimmune disease. Proc. Natl. Acad. Sci. USA. 78:2737-2741.

12. Pisetsky, D. S., and K. F. Semper. 1984. The influence of assay conditions on ELISA determinations of anti-DNA antibodies. J. Immunol. Methods. 74:217-227.

13. Mayus, J. L., and D. S. Pisetsky. 1985. Expression of a highly conserved anti-DNA idiotype in normal and autoimmune mice. Clin. Immunol. Immunopathol. 34:366-378. 
14. Eisenberg, R. A., D. G. Klapper, and P. L. Cohen. 1983. The polypeptide structure of the Sm and RNP nuclear antigens. $\mathrm{Mol}$. Immunol. 20:187-195.

15. Fisher, C. L., R. A. Eisenberg, and P. L. Cohen. 1988. Quantitation and IgG subclass distribution of anti-chromatin autoantibodies in SLE mice. Clin. Immunol. Immunopathol. 46:205-213.

16. Laemmli, U. K. 1970. Cleavage of structural proteins during the assembly of the head of bacteriophage T4. Nature (Lond.). 227:680-684.

17. Theze, J., I. Löwy, M. Seman, C. Brezin, C. Neauport-Sautes, and W. H. Fridman. 1983. Control of isotype expression by helper T-cell clones and suppressor cells. Ann. Inst. Pasteur Immunol. 134D:55-61.

18. Pettersson, I., M. Hinterberger, T. Mimori, E. Gottlieb, and J. A. Steitz. 1984. The structure of mammalian small nuclear ribonucleoproteins. J. Biol. Chem. 259:5907-5914.

19. Habets, W. J., J. H. M. Berden, S. O. Hoch, and W. J. Van Venrooij. 1985. Further characterization and subcellular localization of Sm and U1 ribonucleoprotein antigens. Eur. J. Immunol. 15:992997.

20. Mohn, J. F., R. M. Lambert, H. S. Bowman, and F. W. Brason. 1965. Experimental production in man of autoantibodies with $\mathrm{Rh}$ specificity. Ann. N. Y. Acad. Sci. 124:477-483.

21. Farkas, A. I., G. A. Medgyesi, G. Füst, K. Miklós, and J.
Gergely. 1982. Immunogenicity of antigen complexed with antibody. I. Role of different isotypes. Immunology. 45:483-492.

22. Coulie, P. G., and J. Van Snick. 1985. Enhancement of IgG anti-carrier responses by $\mathrm{IgG} 2$ anti-hapten antibodies in mice. Eur. $J$. Immunol. 15:793-798.

23. Haughton, G., and O. Mäkelä. 1973. Suppression or augmentation of the antihapten response in mice by antibodies of different specificities. J. Exp. Med. 138:103-116.

24. Ter Borg, E. J., G. Horst, E. Hummel, D. Jaarsma, P. C. Limburg, and C. G. M. Kallenberg. 1988. Sequential development of antibodies to specific $\mathrm{Sm}$-polypeptides in a patient with systemic lupus erythematosus: evidence for independent regulation of anti-doublestranded DNA and anti-Sm antibody production. Arthritis Rheum. 31:1563-1567.

25. Cohen, P. L., E. W. Shores, R. A. Eisenberg, and D. S. Pisetsky. 1985. Anti-Sm autoantibodies in MRL mice: analysis of precursor frequency. Cell. Immunol. 96:448-454.

26. Shores, E. W., R. A. Eisenberg, and P. L. Cohen. 1986. Role of the $\mathrm{Sm}$ antigen in the generation of anti-Sm autoantibodies in the SLE-prone MRL mouse. J. Immunol. 136:3662-3667.

27. Shores, E. W., D. S. Pisetsky, J. Grudier, R. A. Eisenberg, and P. L. Cohen. 1988. Immunization with Sm nuclear antigen induces anti-Sm antibodies in normal and MRL mice. Immunology. 65:473478. 